\title{
SWCS CONFERENCE SWCS Annual International ECHOES Conference reflections
}

\author{
Jim Gulliford
}

$\mathbf{T}$ he sun shined on the 67th Annual International Conference of the Soil and Water Conservation Societyliterally and metaphorically. The presence of more than 365 conservation professionals in Fort Worth, Texas, did nothing to mitigate the sunny, $100^{\circ} \mathrm{F}+$ temperatures that have brought drought and yield reductions to many of the cropland acres across the United States. However, the conference presentations and symposia clearly conveyed a bright, positive commitment to addressing the soil and water conservation challenges that scientists, practitioners, and farmers face each day around the globe.

On its surface, the conference theme "Choosing Conservation" may appear to be simple or obvious. We understand the benefits of sound soil and water conservation in terms of agricultural sustainability and environmental protection. Yet, every conservation decision occurs in a context of ecological, economic, and ethical considerations that can be confusing or counterintuitive. In the Pritchard Lecture, Curt Meine spoke fondly of Bennett and Leopold - two giants who were at the heart of the fledgling conservation movement years ago. Their message of scientific application and conservation ethic remains the firm foundation on which today's conservation programs stand. Listen to both Meine's Pritchard Lecture and the day two plenary that examined these issues in the context of today's economy on the SWCS Web site, http://www.swcs.org/12ac.

In addition to the plenary sessions, the Program Committee, chaired by Rebecca Power, assembled an excellent set of workshops, 22 symposia, 74 individual oral presentations, and 44 posters around the theme.

Economic and ethical considerations are important factors that are shaping the debate of the next US Farm Bill. SWCS Washington DC Policy Representative John Peterson joined Jimmy Daukas and Mitch Hunter of the American Farmland

Jim Gulliford is executive director of the Soil and Water Conservation Society, Ankeny, lowa.
Trust presenting an overview of the challenge Congress faces balancing the needs for conservation programs, agricultural research, crop insurance, and food stamp funding. Hunter gave a detailed sideby-side comparison of the conservation program provisions in both the Senate and House versions of the bill.

A report of the lessons learned from the National Institute of Food and AgricultureConservation Effects Assessment Project watershed studies by Deanna Osmond provided insight into farmer and rancher conservation decisions and the measurable results that those decisions produce. Mark Tomer presided over a full-day symposium that examined the challenges of monitoring water quality at the field edge and provided case studies that helped to explain what is being learned about the effectiveness of individual practices and conservation systems thatspecifically target water quality protection.

The conference featured an all-day workshop on soil quality and eco farming. When cropping and conservation systems become one, farmers can balance the ecological, economical, and ethical aspects that are essential to agricultural sustainability and environmental protection. For educators, crop consultants, farmers, and conservation professionals this workshop brought an indepth understanding of the science of soil quality. The workshop was supported in part by the USDA Sustainable Agriculture Research and Education program.

SWCS chapter leaders discussed the opportunities and challenges they face during the House of Delegates meeting. Bill Boyer, SWCS Board of Directors President, provided an assessment of the program direction and sound financial status of the Society. Andy Manale presented information on the availability of two new sets of slides that can be used as teaching tools for the SWCS "Position Statement on Climate Change and Soil and Water Conservation." Produced by Jorge Delgado and the SWCS climate team, these two slide sets offer a brief overview and a more detailed description of the information contained in the report.

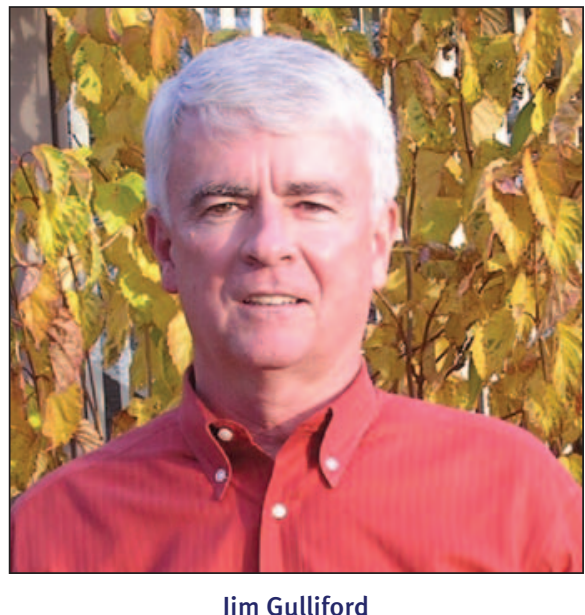

These slide sets are available for chapter and member use on the SWCS Web site http:// www.swcs.org/policy.

At each annual conference, special recognition is given to individuals and chapters for their outstanding contribution to the field of soil and water conservation. Dr. Kenneth Renard received the Hugh Hammond Bennett Award for extraordinary national and international accomplishments in the conservation of soil, water, and related natural resources. Theo Dillaha and Raj Khosla were conferred the title SWCS Fellow for their professional excellence and career contributions to the field of soil and water conservation. A complete listing of this year's award and scholarship recipients can be found on the SWCS Web site, http:// www.swcs.org/awards.

As I look back at this year's conference, it is clear that the sun continues to shine on the work of the Society and its members. The conference provided an opportunity for conservation professionals to learn, interact, exchange ideas, and develop collaborative opportunities. Seeds sown those four days will bear fruit in years to come, producing answers to the ecology, economics, and ethics challenges that face those who make the conservation choice.

We will do it again next year, July 21 to 24, in Reno, Nevada. More information about attending the conference or submitting a presentation is available online at http://www.swcs.org/13ac. Make plans to join us then. 